\title{
Por uma abordagem institucionalista- evolucionária do desenvolvimento econômico: implicações para uma política industrial moderna
}

\author{
José Micaelson Lacerda Morais ${ }^{1}$ \\ Julianne Alvim Milward de Azevedo²
}

\begin{abstract}
Resumo: Objetiva-se apresentar as bases de uma política industrial de corte institucional-evolucionário. Perspectiva, ainda em construção, na qual a política industrial é vista como uma necessidade permanente ditada pelo funcionamento do mercado, concebida como um instrumento de compatibilização entre estabilidade macroeconômica, mudança tecnológica e incremento de competitividade sistêmica, com possibilidades fortemente condicionadas pela estrutura institucional da economia. Constatada que as variações nas relações Estado-sociedade e na organização interna do Estado criam diferentes graus de capacidade para a promoção do desenvolvimento, o impacto da política industrial passa a depender de um conjunto complexo de interdependências socioinstitucionais.
\end{abstract}

Palavras-chave: instituições; política industrial; desenvolvimento.

JEL: D02; E11; O38; O43

\footnotetext{
1 Prof. Associado do Departamento de Economia da Universidade Regional do Cariri - URCA. Doutorado em Economia da Indústria e da Tecnologia pela Universidade Federal do Rio de Janeiro (UFRJ). Pós-doutorado no Centro de Estudos de Desenvolvimento Econômico (Unicamp). E-mail: micaelson_lacerda@yahoo.com.br 2 Professora Adjunta do Departamento de Ciências Administrativas e do Ambiente da Universidade Federal Rural do Rio de Janeiro - Instituto Três Rios (ITR/ UFRRJ). Doutora em Economia (IE/UFRJ) E-mail: juliannemilward@yahoo.com.br
} 


\title{
For an evolutionary- institutionalist approach to economic development: implications for a modern industrial policy
}

\begin{abstract}
This article aims to describe the foundations of an industrial policy of characteristics institutional-evolutionary. Perspective, still in construction, in which the industrial policy is seen as a necessity dictated by the market, designed as a tool for reconciling macroeconomic stability, technological change and increased systemic competitiveness, with possibilities strongly conditioned by the institutional structure of the economy. Found that variations in state-society relations and internal organization of the state create different degrees of capacity for promoting development, the impact of industrial policy is to rely on a complex set of social-institutional interdependencies.
\end{abstract}

Key-words: institutions; industrial policy; development.

JEL: Do2; E11; O38; O43

\section{Introdução}

Em 1898, em seu artigo Why is economics not an evolutionary science?, Veblen já havia percebido que o estudo das instituições deveria está submetido à elaboração de uma ciência evolucionária'. Segundo Lawson (2002), essa, ainda, talvez seja, depois de passados mais de um século, a mais famosa questão em toda história da economia. Através deste ensaio Veblen ficou reconhecido como fundador e "guia" espiritual do institucionalismo americano. Veblen entendia que para que a economia fosse evolucionária deveria também ser institucional, dado que os princípios darwinistas deveriam ser aplicados sobre as instituições. A justificativa para tal assertiva é a de que: como as "propriedades físicas" se mantêm, na linguagem de Veblen, a evolução passa a ser compreendida como a evolução do homem e de suas instituições².

1 "Veblen had two concerns (at least) in posing his famous question. He both (i) believed that economics should be an evolutionary science, that an evolutionary economics would mark an improvement over the existing state of affairs, and (ii) was interested in announcing the inevitability of economics becoming an evolutionary science and in explaining its non-occurrence so far (and indeed its likely form)." (Lawson 2002: 289)

2 Segundo Monasterio (1998) o estilo de Veblen com o uso de frases longas, obscuras, contraditórias, por vezes contendo termos biológicos ou referências antropológicas esdrúxulas, suas idiossincrasias verbais o caracterizaram, por avaliações recentes, como um "deconstructive" projeto em epistemologia. No entanto, argumento contrário é exposto por Lawson (2002: 279): “[...] in matters philosophical at least, Veblen's primary legacy is (i) a constructive program after all (as traditionalists within institutionalism have mostly maintained) albeit one that is (ii) grounded in ontology (as few institutionalists appear explicitly to have argued)". 
O período compreendido entre 1875 a 1925, conforme argumenta Bell (1961: 468-469), "foi extremamente frutífero e cheio de acontecimentos em todas as fases da empresa humana [...] [e] as tendências de um estado dinâmico em crescimento foram provavelmente vistas com mais clareza por Veblen do que por qualquer outro pensador do período." Veblen estava preocupado em apreender os fatores imateriais que influenciavam a esfera socioeconômica, ou seja, os elementos que não são encontrados na realidade material, strictu senso. Atribui-se, assim, aos seus escritos e aos trabalhos de Commons, Mitchel, Ayres, entre outros, a matriz da Escola Institucionalista. Escola que, entre 1920 e 1930, teve grande repercussão nos meios acadêmicos norteamericanos $^{3}$, e como afirma Blaug (1993: 124), até "[...] ameaçou tornar-se a corrente dominante do pensamento econômico americano".

Todavia, com a Revolução Keynesiana a escola institucionalista entrou em crise. De acordo com Monasterio (1998: 9),

[...] no pós-guerra, o termo institucionalismo foi utilizado sem muito rigor, e passou a designar os economistas heterodoxos não-marxistas que enfatizavam o papel das organizações e da cultura no processo econômico, como, por exemplo, John Kenneth Galbraith ou Gunnar Myrdal.

Durante um período aproximado de 40 anos a economia institucional ficou fortemente desacreditada, até o surgimento de novas abordagens como a Nova Economia Institucional e o Neo-institucionalismo. A importância das instituições para o funcionamento dos sistemas econômicos e seu desenvolvimento voltou então, a merecer destaque no mundo acadêmico nos últimos trinta anos, com várias contribuições importantes para o campo da teoria econômica.

Este artigo não tem a pretensão de resenhar completamente o pensamento evolucionista e institucionalista, nem histórica nem teoricamente. Mas, tem como objetivo principal apresentar as bases de uma política industrial moderna sob um referencial institucionalista-evolucionário. Para tanto, encontra-se dividido em cinco partes além desta introdução. Na segunda seção são discutidos os pontos de contacto entre o institucionalismo e a economia evolucionária passando em seguida, seção três, para uma apreciação da relação entre instituições e desenvolvimento. Na terceira e quarta seções discute-se a política industrial numa perspectiva institucionalista-evolucionária. Por fim, tecem-se algumas breves conclusões e cita-se a bibliografia utilizada.

3 De acordo com Rutherford (2005: 2), "It is now recognized that institutional economics was a significant movement within American economics during the interwar period. Institutional economics in this period was not a marginalized heterodoxy to a dominant neoclassical orthodoxy, but a very substantial part of what was a relatively pluralistic mainstream of American economics." 


\section{O institucionalismo e a economia evolucionária}

Na Economia, em geral, as concepções que têm as instituições como unidade de análise partem da discussão de suas diferenças com o neoclassicismo e suas afinidades com o evolucionismo, buscando identificar analiticamente pontos de concordância que permitam a constituição de uma possível "teoria institucionalista". Conceição (2001) aponta para cinco abordagens institucionalistas: os neo-institucionalistas; os neo-schumpeterianos ou evolucionários $^{4}$; os regulacionistas; e a economia das convenções ${ }^{5}$; e a Nova Economia Institucional (a exceção às demais por possuir inspiração neoclássica). Em resumo, a enorme corrente que sucedeu Veblen, Commons e Mitchell assumiu diferentes nuanças conceituais e metodológicas, nem sempre absolutamente compatíveis.

De forma sintética, as correntes institucionalistas, propriamente ditas, podem ser agrupadas em três grandes grupos: 1) o "antigo" institucionalismo norteamericano de Veblen, Commons e Mitchel; 2) a nova economia institucional (NEI) de Coase, Williamson e North; e 3) O neo-institucionalismo de Galbraith, Grunchy, Hodgson, Samuels e Rutherford. Entretanto, Théret (2003), afirma que há uma configuração tripolar isomorfa no campo da Economia que se apresenta de forma particular em diferentes casos nacionais. No caso francês, especificamente, os novos institucionalismos da economia estão representados na tríade: nova economia institucional/economia das convenções/teoria da regulação ${ }^{6}$.

A idéia de evolução em Veblen está intimamente associada à de "processo de causação circular". Veblen salientava que a história da vida econômica dos indivíduos se constituía em um "processo cumulativo de adaptação dos meios aos fins, que, cumulativamente, se modificava, enquanto o processo avançava7." Isto implica reconhecer que Veblen adotou uma posição pósdarwiniana, enfatizando o caráter de “processo de causação” tão comum na concepção evolucionária.

Em Veblen a história “evolui” enquanto processo "absurdo" (absurdist), com uma trajetória “cega”, inexistindo qualquer movimento dialético, que leve à rupturas preestabelecidas ou "redentoras", muito menos a qualquer processo determinístico de "progresso". Em realidade, a "cegueira" é fruto ou parte de um processo de permanente mudança e adaptação, realizada em meio à incerteza. (Conceição 2001: 94 e 95)

4 Conceição (2001: 22), afirma que os paradigmas tecnológicos propostos pelos neo-schumpeterianos “[...] se constituem em um autêntico "estudo de caso institucionalista", por incorporar as noções essenciais implícitas nas diferentes abordagens institucionalistas. A mudança tecnológica, o conceito de inovação, o papel evolucionário da firma, o processo de destruição-criadora, o papel do "empresário-inovador" vis-à-vis ao do moderno "sistema nacional de inovação" são noções destituídas de sentido sem a presença de instituições ou do ambiente institucional [...]”.

5 Villeval (1995), incorpora a esta lista a nova economia industrial (lewis, Schelling, Schotter, Shubik) e os austríacos (Hayek e Menger).

6 Interessa observar que este autor trata todos os representantes destas abordagens sobre o rótulo de novos institucionalistas, o mesmo se faz no restante deste item.

7 Veblen (1898). 
MORAIS, J.; AZEVEDO, J. Por uma abordagem institucionalista-evolucionária....

Nesse sentido, se considera, por um lado, as abordagens evolucionária e institucionalista como convergentes e, por outro, a abordagem do mainstream, há no plano teórico duas visões de crescimento em permanente tensão: 1) dos que veem o mundo real como resultante de um processo permanente de mudança e desenvolvimento (evolucionistas e institucionalistas) e; 2) dos que contemplam as proposições lógicas das teorias do crescimento de equilíbrio de steady state.

Na tradição institucionalista a história importa, as formas de crescimento capitalista são diferenciadas, o processo de crescimento é continuo e tem profundas raízes históricas no aparato institucional e social. Na abordagem evolucionária o desenvolvimento econômico é um processo multifacetado e a mudança tecnológica, as características e comportamento das firmas e instituições são fundamentais para o respectivo processo, definindo também como na tradição institucionalista, um conjunto de padrões específicos e diferenciados de crescimento. Logo, as possibilidades abertas por estas duas visões apontam para a necessidade da construção de uma nova agenda (em desenvolvimento) para as teorias do crescimento que produzam uma teorização mais provocativa sobre tecnologia, firmas e instituições, como um novo campo teórico, de conformação mais apreciativa do que formal.

\section{Instituições e desenvolvimento numa perspectiva evolucionária}

Segundo Evans e Chang (2000), todos reconhecem que as instituições são fundamentais para a transformação econômica bem como para o equilíbrio da economia. Mas, até se chegar a uma teoria satisfatória das instituições e dos seus efeitos econômicos ainda há um grande caminho a ser percorrido. Segundo eles, a corrente teórica do mainstream econômico geralmente não pensa em instituições, mas até onde eles fazem, as instituições são vistas como "restrições" em relação ao funcionamento do livre mercado que criam "rigidezes" e conseqüentemente ineficiência. O que é surpreendente, como eles enfatizam, é que tal retórica de "instituições como constrangimentos", também é defendida por muitos economistas institucionalistas que apóiam a denominada Nova Economia Institucional, como North e Williamson. Porém, empregando a retórica de "constrangimentos", eles ainda mantêm o mito de que o mercado é a ordem natural que deve prevalecer, enquanto instituições são substitutas artificiais que deveriam ser acionadas quando o mercado apresenta falhas. Não que Chang e Evans estejam negando que as instituições não imponha constrangimento, mas principalmente, que as instituições devem ser vistas também como estímulos, nas palavras dos autores enabling devices.

Às visões das instituições como constrainting e como enabling, os autores acima adicionam uma terceira visão das instituições como constitutive, a qual 
MORAIS, J.; AZEVEDO, J. Por uma abordagem institucionalista-evolucionária....

os economistas dão pouca atenção, mas que é fundamental para a análise que estes autores fazem do papel das instituições na mudança econômica. Refere-se à dimensão simbólica das instituições que é percebida em certos valores ou visões de mundo e que moldam o comportamento das pessoas que vivem sob elas. Se as pessoas agissem somente visando o seu interesse econômico imediato, não respeitando as instituições, o custo de monitorar os possíveis desvios e aplicar punições seria insustentável. Estas três visões de instituições não são mutuamente exclusivas. Assim, não há nenhuma inconsistência ao dizer que as instituições estão constrangendo, habilitando, e atuando como constituivas ao mesmo tempo. E realmente a menos que se reconheçam estes três aspectos, a análise das instituições não estará completa. Assim, para estes autores, a mudança institucional depende da combinação de interesses e projetos ideológicos/culturais de difícil teorização. Portanto, para alterar instituições são necessárias mudanças nas visões de mundo que são subjacentes as estruturas institucionais.

Burlamaqui e Fagundes (1996: 157), seguindo na mesma linda da discussão acima afirmam que apesar de "instável, complexa e de difícil teorização, a relação entre instituições, estabilidade e eficiência pode [...], ser organizada de uma forma um pouco menos imprecisa, se nela forem introduzidos os conceitos de isomorfismo e congruência”.

Para qualificar o argumento de Burlamaqui e Fagundes (1996), faz-se necessária entender a posição destes autores quanto à importância das instituições para o processo de desenvolvimento:

[...] são as instituições que constroem os espaços onde as relações econômicas têm lugar. São instituições que estruturam os incentivos, e delimitam as fronteiras, para as atividades e a ação coletiva numa sociedade; sejam elas econômicas, políticas, culturais ou religiosas. Desse modo, as mudanças institucionais condicionam as formas através das quais as sociedades evoluem no tempo, e por essa via afetam seu desempenho econômico. (Burlamaqui e Fagundes, 1996: 148)

Portanto, as instituições desempenham um papel central na medida em que co-organizam as interações entre os agentes econômicos no processo produtivo e no mercado. Também, para Burlamaqui e Fagundes (1996), as instituições são canais que modelam a "visão de mundo", as expectativas e os comportamentos dos indivíduos e das empresas, condicionando suas ações no meio ambiente onde atuam.

Os autores acima citados entendem por isomorfismo institucional, a existência de compatibilidade entre os princípios de funcionamento de um conjunto de instituições, de modo a configurar um resultado sistêmico, internamente coerente. Já a congruência institucional, é utilizada para definir constelações ou arquiteturas institucionais cujos objetivos apontam para a mesma direção. Como estabilidade e a eficiência não são fenômenos necessariamente 
MORAIS, J.; AZEVEDO, J. Por uma abordagem institucionalista-evolucionária....

sincrônicos, a sua integração que é também um fenômeno mutuante e complexo, depende da presença de uma constelação institucional isomórfica e da existência de uma arquitetura institucional congruente" (Burlamaqui e Fagundes 1996: 158). Estes dois conceitos permitem definir, por exemplo, o que Kupfer (2004: 2) denomina de regime competitivo:

[...] uma estrutura de incentivos e regulação da concorrência, correspondendo ao rebatimento no plano microeconômico dos parâmetros que regulam o grau de abertura econômica de uma nação [que] envolvem, via de regra, a definição do nível e estrutura de proteção tarifária e não tarifária das importações, da carga tributária, da taxa de cambio, das taxas de juros e das condições gerais de acesso ao capital doméstico e internacional, incluindo o investimento direto externo, além de um conjunto de normas e instituições que regulam a atuação de monopólios e oligopólios, os direitos de propriedade e muitos outros aspectos.

De forma geral, o conceito de desenvolvimento defendido aqui é definido pela relação entre a capacidade produtiva local e uma reordenação global dos setores industriais e não como mera trajetória local de transformação. O que por sua vez, implica na redefinição da gama de produtos que uma região ou um país produza e dos mecanismos de transmissão destes para o desenvolvimento. Por esta visão, os países desenvolvidos são aqueles que preenchem os nichos setoriais mais dinâmicos e lucrativos, ou seja, são aqueles que desenvolvem vantagens dinâmicas. Mas, "a emergência de vantagens comparativas depende de uma evolução complexa envolvendo processos competitivos, vínculos de cooperação entre empresas locais, políticas governamentais e de um conjunto de instituições e arranjos sociais e políticos" (Evans 2004: 34).

Nesse processo, a política do Estado não apenas muda o comportamento dos atores existentes, mas também ajuda a trazer para a sociedade atores sem os quais o desenvolvimento industrial seria impossível. O Estado pela sua abrangência e legitimidade, se apresenta como entidade privilegiada para o exercício de catalisação de forças através de sua atuação na coordenação de última instância de estratégias empresariais, e na consolidação dos pactos necessários à sua concretização, destacando as potencialidades de uma integração dinâmica entre estrutura industrial e estratégias empresariais. Dessa forma, um papel governamental mais ativista pode ser um fator decisivo para um crescimento industrial mais acelerado. A combinação incentivos/ exigência de desempenho não apenas define o comportamento das atividades industriais existentes como também permite ao Estado dar vida a um conjunto de grupos empresariais que venha a viabilizar um projeto conjunto de transformação industrial.

Dentro do referencial institucionalista, a principal referência adotada aqui é a de que a economia exige o Estado para sua constituição. Isto porque a divisão crescente do trabalho nas economias contemporâneas exige o desenvolvimento de uma estrutura institucional que dê conta do aumento 
MORAIS, J.; AZEVEDO, J. Por uma abordagem institucionalista-evolucionária....

da complexidade nas interações entre os agentes econômicos. A base desta complexidade reside no estabelecimento, atribuição e garantia dos direitos de propriedade, papel exercido pelo Estado através do monopólio da força. Assim, quanto melhor definidos, atribuídos e garantidos estes direitos, menores os custos de transação, o que não significa dizer que para a promoção da atividade econômica e da riqueza dos agentes o Estado não deva ter uma intervenção mais ativa.

Evans (2004: 28), afirma que "sem o Estado, o mercado, a outra instituiçãochave da sociedade moderna, não funciona." Nesse sentido, a pergunta que surge imediatamente é: quais as características que os Estados assumem e como contribuem para o processo de desenvolvimento, em particular o industrial? Isto porque, para este autor, o Estado mesmo que de forma imperfeita permanecerá no centro das soluções dos problemas da vida coletiva, até que sejam descobertas outras maneiras menos hierarquizadas de assegurar o interesse geral sobre o particular, de prover os bens coletivos e de sustentar os processos de transação. Isto porque, o Estado constitui-se na representação mais abrangente das instituições e também na arena a partir da qual são traçados os seus limites de atuação, de associações e de outras instituições e indivíduos.

Na abordagem de Evans (2004), a estrutura interna do Estado e o caráter das relações Estado-sociedade são os dois elementos de análise que permitem entender o papel do Estado no desenvolvimento. O ponto de partida para análise da estrutura interna reside na hipótese weberiana sobre o papel da burocracia. Por esta visão, é a insuficiência de burocracia que prejudica o desenvolvimento e não a sua prevalência. A burocracia, ou mais genericamente o aparato organizacional do Estado, é vista pelo referido autor como um conjunto de normas e estruturas que induzem à competência.

Para Evans (2004), portanto, a questão de como a autonomia e a inserção social, em outras palavras estrutura interna do Estado e as relações Estadosociedade, podem ser eficientemente combinadas constitui o cerne da análise do desenvolvimento, que de longe é a mais complicada em termos de análise pelas posições conflitantes que surgem a nível teórico. Em seu estudo constatou que as diferenças nas formas de intervenção dependem das várias formas que o próprio Estado assume. Tipos diferentes de estruturas geram capacidades diferenciadas de ação. Para caracterizar as diferentes formas de estrutura do Estado e das relações Estado-sociedade, dentro de um marco institucionalcomparativo, ele desenvolveu dois tipos polares historicamente idealizados, denominados de Estados predadores e Estados desenvolvimentistas, grosso modo, assim caracterizados:

[...] os Estados predadores conseguem, às custas da sociedade, refrear deliberadamente o processo de desenvolvimento, mesmo em sua dimensão mais estreita de acumulação de capital. Os Estados desenvolvimentistas, por sua vez, 
MORAIS, J.; AZEVEDO, J. Por uma abordagem institucionalista-evolucionária....

não apenas direcionam a transformação industrial, mas também, como pode ser argumentado de forma plausível, são em grande parte responsáveis pelo desenvolvimento (Evans 2004: 37).

Por seu turno, a organização interna dos Estados desenvolvimentistas está assentada nas conexões entre o "povo" e o Estado como organização que envolve um conjunto concreto de alianças sociais que ligam o Estado à sociedade através de canais institucionalizados para negociação contínua de objetivos e planos de ação, o que supõe uma administração burocrática moderna, semelhante à burocracia weberiana. Assim, justapor Estados 'predatórios' e 'desenvolvimentistas', segundo Evans, permite mostrar como a organização interna e as relações com a sociedade produzem impactos desenvolvimentistas distintos. No sentido que aqueles Estados que extraem grandes quantias de seus cidadãos para privilégios privados acabam por impedir a transformação econômica. De outra forma, aqueles Estados em que estimulam a perspectiva empresarial das suas elites, aumentando os incentivos e reduzindo os riscos, propiciam condições para que estas elites se comprometam com investimentos transformadores. Como arquétipo de Estado predatório, Evans (2004) descreveu o Zaire e como arquétipo de Estado desenvolvimentista, mostrou como exemplo o Japão.

Evans (2004), ainda estabeleceu uma classificação intermediária para aqueles Estados que se colocam numa posição entre os Estados predadores e os Estados desenvolvimentistas, como é o caso do Brasil e da Índia. O autor sugere que deve haver alguma semelhança da organização burocrática destes países com aquelas encontradas no leste asiático, mas não em um grau de coerência corporativa usufruída por estes últimos. Nesse sentido, o que prevalece é um equilíbrio contraditório entre autonomia e parceria que podem tomar tanto a forma de um clientelismo excessivo quanto da incapacidade da construção de projetos conjuntos com as elites industriais.

Em resumo, as variações nas relações Estado-sociedade e na organização interna do Estado criam diferentes graus de capacidade para promover o desenvolvimento e as conseqüências da intervenção do Estado dependem de que tipo de intervenção é tentada, o tipo de Estado e o seu contexto. A própria legitimidade do Estado e de seus dirigentes depende do efetivo desenvolvimento industrial. Neste sentido, as abordagens de Bularmaqui, Fagundes e Evans se aproximam.

Por essa perspectiva, a política econômica, em especial a política industrial, passa a ser vista como uma necessidade permanente ditada pelo funcionamento do mercado, concebida como um instrumento de compatibilização entre estabilidade macroeconômica, mudança tecnológica e incremento de competitividade sistêmica num contexto de incertezas e volatilidade potencial de expectativas. No entanto, as suas possibilidades são fortemente condicionadas pela estrutura institucional da economia, por seu grau de isomorfismo 
MORAIS, J.; AZEVEDO, J. Por uma abordagem institucionalista-evolucionária....

(coerência), e pelos canais de comunicação existentes intra-setor e entre a iniciativa privada e o setor público. Essa proposição põe em evidência que o seu âmbito de atuação é extremamente amplo, atravessando diagonalmente o aparelho produtivo, inclusive os aspectos de infraestrutura. Em sua base conceitual, a estratégia de coordenação via instituições, envolve, necessariamente, tanto medidas horizontais, quanto setoriais, sendo que a relação entre ambas deve ser de complementaridade e não de exclusão (Burlamaqui \& Fagundes 1996; Gadelha 2002). Desta perspectiva, os elementos com os quais a política econômica opera não implicam uniformidade operacional ou comportamental, mas convergência de expectativas e cooperação, institucionalmente construídas.

\section{Uma política industrial evolucionária}

A contribuição neo-schumpetiriana providenciou tanto uma teoria da mudança e inovação tecnológica quanto uma nova teoria microeconômica da firma, também estabelecendo amplas referências com o ambiente institucional, explicitando uma importante e decisiva fonte de interação com as modernas versões institucionalistas. O vínculo estreito que estabelecem com a história permite o tratamento da diversidade dos agentes e do contexto social, econômico e institucional no qual estão inseridos, oferecendo possibilidades de proposições normativas muito mais ricas que a mera correção de falhas de mercado ou de um Estado mínimo, como ocorre com a teoria neoclássica e com os partidários do neo-utilitarismo. Fornece, portanto, elementos conceituais que contribuem para pensar a política econômica, em especial a política industrial, considerando a diversidade setorial, tecnológica, comportamental e institucional presente nas distintas formações capitalistas.

Conceição (2001) entende que há uma clara preocupação dos evolucionários com a inter-relação entre desenvolvimento, inovação tecnológica e aparato institucional, tornando possível a inserção das instituições no ambiente teórico evolucionário, a exemplo da agenda de pesquisa proposta por Nelson.

[...] a conceituação de paradigma tecno-econômico proposta pela contribuição neo-schumpeteriana se constitui na forma teoricamente mais elaborada de incorporação das instituições ao processo de mudança e crescimento econômico. Isto porque essa abordagem explicita a necessidade de se compreender o processo de desenvolvimento econômico como intrinsecamente "produzido" pela interação entre "aparato institucional" e mudanças tecnológicas, econômicas e sociais. Como o ambiente institucional é mutável, conforme o padrão tecnológico existente, depreende-se que as análises institucionalistas só têm sentido em "contextos teóricos" que contemplem o processo de mudança, já que esta é crucial para a dinâmica do crescimento econômico. Vale dizer: dinâmica pressupõe mudança tecnológica e institucional. E tal pressuposto analítico é teoricamente explorado na análise evolucionária. (Conceição, 2001: 22) 
Corroborando esta perspectiva, Baptista (2000), afirma que a visão schumpeteriana da concorrência e da dinâmica do sistema capitalista inspirou a produção teórica de um conjunto amplo e crescente de autores, os neo-schumpeterianos, que particularmente, desde o início dos anos 1980, transformou-se numa vertente teórica consistente e de abrangência considerável para explicação dos problemas econômicos. Seja para a análise da dinâmica e transformação estrutural dos mercados, da firma ou, mais recentemente, para a elaboração de modelos de crescimento.

Na perspectiva neo-schupeteriana a questão do desenvolvimento enfatiza mudanças qualitativas em termos tecnológicos, organizacionais e institucionais. $\mathrm{O}$ foco é voltado para a evolução competitiva de diferentes regiões e países, centrada nas inovações, movida pelo objetivo de obtenção de rendas monopolistas. É nesse âmbito definido pela dinâmica das inovações que se dá a discussão sobre a questão do crescimento e do desenvolvimento econômico. O progresso técnico apresenta uma forte característica de cumulatividade, sendo que o resultado obtido num período depende do estágio do desenvolvimento alcançado no período anterior, conformando trajetórias tecnológicas que afetam a atividade macroeconômica em seu conjunto e as trajetórias nacionais de crescimento e desenvolvimento.

Por seu turno, o desenvolvimento e o impacto da política industrial dependem de um conjunto complexo de interdependências sócio-institucionais que condicionam as trajetórias nacionais. A evolução dos distintos segmentos produtivos e regimes tecnológicos associam-se a estruturas sócioinstitucionais particulares e assim, a institucionalidade que marca os distintos sistemas nacionais de inovações condiciona os padrões de evolução dos diferentes ramos produtivos. A estrutura sócio-institucional impacta na atividade econômica não apenas de forma genérica, mas também a partir de seu interior, moldando o comportamento dos agentes e a lógica competitiva vigentes nos diferentes mercados.

De acordo com Gadelha (1999), as concepções que privilegiam a estrutura econômica e institucional que condicionam os processos cumulativos de inovação, difusão e aprendizado, como a de Freman e Lundvall, compartilham o foco na inovação e no aprendizado, a adoção de uma visão abrangente, histórica e institucional, que definem o caráter sistêmico, interdependente e não linear das trajetórias nacionais e a necessidade de tratar as instituições e as organizações no âmago da análise econômica da evolução tecnológica dos distintos países. A incorporação de instituições, para tornar-se relevante, deve basear-se na própria constituição dos Estados nacionais, envolvendo uma lógica social que extrapola a racionalidade meramente econômica. Uma análise mais rigorosa deve privilegiar as características da estrutura produtiva, as trajetórias tecnológicas dos agentes nos distintos setores e os condicionantes institucionais da microdinâmica de transformação. Pois, a base tecnológica, industrial e institucional existente condiciona a capacitação 
MORAIS, J.; AZEVEDO, J. Por uma abordagem institucionalista-evolucionária....

tecnológica formal e tácita dos países e regiões, determinando a evolução das trajetórias setoriais e a competitividade.

Em seu trabalho de tese, Gadelha (1999), propõe-se a desenvolver uma relação entre política industrial e desenvolvimento a partir de uma perspectiva Neo-Schumpeteriana. Para tanto, faz uma proposta analítica centrada na concorrência e no progresso técnico através da tentativa de sistematização de uma visão evolucionista do desenvolvimento. Ao realizar uma ampla revisão da literatura evolucionista, o autor identifica três lógicas presentes na evolução econômica, que embora distintas do ponto de vista analítico, são a seu entender fundamentais para tratar as questões do desenvolvimento: "a da demanda efetiva, a de transformação qualitativa da estrutura produtiva (associada às inovações) e a da dinâmica institucional, que incorpora o papel das organizações e das regras de conduta socialmente incrustadas na dinâmica econômica" (1999: 53).

Em resumo, no processo de desenvolvimento presencia-se um elevado dinamismo da demanda e de investimentos, uma transformação tecnológica significativa da estrutura produtiva e uma evolução das instituições e das normas comportamentais dos agentes favoráveis ao processo de expansão econômica. O processo é co-evolutivo no sentido de que há uma convergência entre a introdução de novas tecnologias, de novas formas de organização da produção e de novas formas institucionais. Está, portanto, na articulação dos aspectos institucionais com a estrutura produtiva, mediadas sob a influência do binômio concorrência/progresso técnico, a fonte das transformações econômicas que podem ser observadas a partir das distintas trajetórias tecnológicas possíveis dada esta articulação. O desenvolvimento é entendido, assim, como a promoção de mudanças qualitativas nas rotinas e estruturas de mercado que vão além dos horizontes existentes, que longe de ser um processo natural e suave, envolve a presença de novos setores, novas tecnologias, novos comportamentos por parte dos agentes e instituições. Neste processo, as novas tecnologias impõem novos requerimentos institucionais, envolvendo novas formas de regulação, novos mecanismos de incentivos e de punição e novas estruturas organizacionais, que demandam uma permanente ação da esfera pública num sentido ativo e positivo de promoção do mercado como um veículo essencial à geração de inovações de produtos, processos e institucionais.

[...] o que se está querendo mostrar é que a estrutura econômica mediada pela concorrência permite a incorporação das instituições pela teoria econômica, viabilizando um certo nível de generalidade imprescindível ao tratamento analítico. Ou seja, a concorrência, simultaneamente, produz variedade e assimetrias e impõe uma regularidade na vida econômica, tornando-a, portanto, inteligível [...] uma vez que as forças da concorrência associadas às distintas estruturas impõem limites e exigem certos imperativos à organização institucional dos mercados. (Gadelha 1999: 61) 
Por fim, cabe destacar novamente que a ação do Estado não decorre de necessidades funcionais das falhas de mercado, mas sim do seu poder político para mediar as relações entre os agentes, no sentido de condicionar as estratégias privadas, a configuração dos mercados e o desenvolvimento de modo geral. O Estado, como uma instituição privilegiada, dado que é a instância de poder dos sistemas nacionais, possui a capacidade de articular os agentes e instituições em torno de trajetórias de desenvolvimento, contribuindo de forma decisiva para o processo co-evolutivo de desenvolvimento. "Todas as experiências capitalistas bem sucedidas se valeram de Estados nacionais fortes que tiveram um papel central na articulação dos interesses em torno [de] uma determinada direção evolutiva" (Gadelha 1999: 105).

Coloca-se, assim, como uma dimensão essencial a discussão da organização, da forma de intervenção e da reforma do Estado que condicionam o resultado de uma política pública. Mas, o comportamento do Estado também está sujeito a erros, a correção de rumos e ao aprendizado. Porque o Estado também sofre de limitação cognitiva em seu processo de compreensão da realidade e de intervenção, uma vez que está imerso na incerteza e na complexidade ambiental, e a sua ação está condicionada pela estrutura econômica e tecnológica vigente e pela base organizacional e trajetória histórica da burocracia e da política pública que limitam seu horizonte de atuação.

Através da análise realizada neste item foi possível observar que o pensamento institucionalista funde-se com o evolucionário em muitos aspectos e noções. A crítica ao equilíbrio de longo prazo como meta finalística do processo de crescimento traduziu-se no grande legado do "antigo institucionalismo", cuja contribuição dos neo-schumpeterianos ou evolucionários, mesmo sem pretender ser "institucionalista", tratou de dar substância e consistência teórica.

Em resumo, a tese defendida é a de que ambientes institucionais distintos definem padrões de crescimento diferenciados e nesse processo as instituições são fundamentais para a compreensão de possíveis e sempre diferenciadas trajetórias de crescimento econômico. Tentar compreendê-las sem instituições carece de sentido lógico, teórico e histórico. Se, para os evolucionários, as instituições, de um lado, não se constituem em "unidade central de análise" - como o fazem as abordagens institucionalistas -, de outro, constituem-se em elementos indissociáveis do processo dinâmico de crescimento e mudança tecnológica.

\section{Por uma nova política industrial institucional- evolucionária}

Segundo Possas (1996), o tema da competitividade tem tido presença marcante e crescente na literatura econômica do desempenho da empresa e a ênfase 
MORAIS, J.; AZEVEDO, J. Por uma abordagem institucionalista-evolucionária....

nos seus fatores sistêmicos desloca o foco das empresas e indústrias para as condições de ambiente competitivo, sistema econômico/institucional e infraestruturas que geram externalidades para as empresas. A competitividade deve ser assim um objetivo da política industrial. Nesta mesma direção, Kupfer (2003: 281-82), entende que:

[...] cabe à política industrial acelerar os processos de transformação produtiva que as forças de mercado podem operar, mas o fazem com lentidão, e disparar processos que essas mesmas forças são incapazes de articular [...] está claro hoje que os investimentos produtivos, sem o auxílio de políticas específicas, virão muito mais lentamente ou simplesmente não virão [...].

1) o sucesso do desenvolvimento asiático na década de 1980, que forçou os economistas a incluírem as instituições públicas nos modelos de desenvolvimento, e mais recentemente a estratégia chinesa que não prescindiu do planejamento, empresas estatais, controle direto sobre fluxos monetários e investimentos e realizado sob a liderança de um partido/Estado que detém, ainda, o monopólio da terra;

2) a importância do progresso técnico e do aprendizado como fontes de eficiência (retornos crescentes de escala associados ao avanço do progresso técnico, que implicam espaços justificáveis para a ação do Estado);

3) o entendimento que há restrições ao funcionamento do mercado sob as quais se dá a atuação do Estado, tais como: a existência de racionalidade limitada, de informação imperfeita e de interesses múltiplos, que implicam maiores espaços para entender e melhorar a qualidade da ação pública;

4) o fato de a década de 1990 ter demonstrado que somente a estabilidade macroeconômica não se apresenta como condição suficiente para promover a mudança estrutural da economia e do padrão exportador do país em termos dinâmicos.

Portanto, seja através do reconhecimento da importância das instituições, das questões relacionadas ao progresso técnico ou ao funcionamento dos mercados, há justificativas suficientes que demonstram a responsabilidade histórica do Estado-nação no processo de transformação econômica da sociedade. No caso das posições menos intervencionistas, a defesa das ações do governo apenas é justificada para a correção das falhas de mercado: i) a existência de economias de escala; ii) a existência de externalidades; iii) a existência de bens públicos; iv) informação imperfeita e assimétrica; e v) incerteza. Segundo esta corrente, ainda que a existência destas falhas justifique a execução de uma política industrial por parte do governo, esta não deveria ser utilizada. Isto porque a existência de falhas de governo poderia levar a uma situação em que a intervenção estatal provocasse ainda maiores prejuízos ao mercado. 
A vertente neoclássica mais sofisticada, conhecida como a teoria do rent seeking, afirma que a ação do Estado na concessão de direitos de propriedade possui efeitos nocivos do ponto de vista da eficiência econômica ao estimular o desperdício de recursos escassos. No entanto, como afirma Fiani (2003), a defesa de políticas públicas, notadamente em favor da desregulação econômica, por parte desta teoria, se mostra inadequada por duas razões: indeterminação desses modelos e conclusões que não possuem um caráter geral. Pois,

[...] a teoria de rent seeking admite um conjunto muito particular de direitos de propriedade: os direitos de natureza monopólica ou que implicam em restrições comerciais, ignorando outros direitos concedidos pelo Estado, que implicam na proteção às rendas geradas por inovações de produtos e de processos, ou na racionalização econômica dos recursos em commom pool.” (Fiani, 2003: 19).

O A intervenção do Estado, segundo a teoria tradicional, também se justificaria em nível regulatório (defesa da concorrência), principalmente, no que diz respeito ao comércio exterior. Em geral, este grupo de teóricos defende a especialização dos países nos setores nos quais possuam vantagens comparativas reveladas, que estando dadas para cada país não poderiam ser modificadas ou se alterariam apenas com determinadas políticas horizontais.

Por outro lado, as abordagens mais intervencionistas defendem um papel mais ativo do Estado, no qual a política industrial pode ter um papel fundamental na construção de vantagens comparativas dinâmicas em oposição às vantagens comparativas estáticas. Para isso, o principal instrumento seria o conhecimento e a inovação tecnológica, vista como principal elemento dinamizador da atividade econômica capitalista. Para Além, Barros, Giambiagi (2002), a política industrial assume um papel estratégico à medida que permite a coordenação dos agentes produtivos que precisam tomar decisões cruciais como investir e/ou inovar em um ambiente permeado de incerteza quantos aos resultados futuros de suas decisões.

Em resumo, a política industrial seja ela implícita ou explícita está diretamente ligada à capacidade institucional do Estado-nação em pensar e repensar o seu desenvolvimento autônomo. A política industrial deixa de ter um caráter contingente, como pensa a teoria econômica tradicional, e passa a ser uma preocupação constante do Estado em atingir e/ou manter um certo padrão de desenvolvimento, dado que é no sistema industrial que ocorre o desenvolvimento tecnológico e a sua difusão pelos demais setores econômicos.

Apresenta-se premente a necessidade de recuperar a capacidade institucional do Estado-nação como agente e coordenador do desenvolvimento industrial e tecnológico através da definição de um conjunto de políticas econômicas bem definidas (horizontais e verticais) e sujeitas à coordenação institucional capaz de dinamizar a economia como um todo e minimizar os conflitos estaduais, mantendo a capacidade dos últimos de implementar suas 
MORAIS, J.; AZEVEDO, J. Por uma abordagem institucionalista-evolucionária....

próprias estratégias. Citando Kupfer (2003: 296), "há a necessidade de reconstruir a institucionalidade da política industrial." Os instrumentos a serem utilizados estão relacionados a um sistema de incentivos e regulações. $\mathrm{O}$ primeiro relaciona-se a medidas fiscais e financeiras, como incentivos à pesquisa e desenvolvimento, crédito, compras governamentais e estímulo à exportação, tanto em termos de políticas horizontais como verticais. Já o regime de regulação relaciona-se à manutenção de um ambiente competitivo, englobando as políticas antitrustes, comercial, de propriedade intelectual, consumidor e meio ambiente.

Observa-se, também, que os instrumentos de política industrial são concebidos num contexto macroeconômico que determinam o padrão de desenvolvimento de um país. Neste macro ambiente em que se definem as políticas que lidam com o comportamento agregado da economia (inflação, taxa de câmbio e de juros, carga tributária e investimentos) relacionadas diretamente com as políticas fiscais, monetárias e cambiais, insere-se também a política industrial, que depende deste macro ambiente e da orientação geral destas políticas, mas não se deve confundi-las com a política industrial. Dado que

política industrial é a criação, a implementação, a coordenação e o controle estratégico de instrumentos destinados a ampliar a capacidade produtiva e comercial da indústria, a fim de garantir condições concorrenciais sustentáveis nos mercados interno e externos [...] está fundada em instrumentos microeconômicos [...] tem como objeto de intervenção atividades econômicas específicas ou setoriais [...] e em temas que diretamente afetam a sua competitividade e função social (geração de empregos, qualidade de produtos e processos, incentivos fiscais e financeiros, suprimento energético e de transporte, infra-estrutura tecnológica e meio ambiente). (Campanário \& Muniz da Silva 2004: 14).

Costuma-se, também, classificar as políticas industriais em horizontais e verticais/setoriais. As primeiras abrangem uma série de medidas que impactam a indústria e, em linhas gerais, a própria economia como um todo. Já as políticas verticais ou setoriais, têm como objetivo o incentivo a setores industriais específicos. O primeiro caso envolve as políticas macroeconômicas ou de promoção da competitividade sistêmica constituídas, basicamente, de instrumentos horizontais, que têm impacto no sistema econômico como um todo, tais como:

i) estabilidade de preços;

ii) eficiente sistema tributário;

iii) acesso a fontes de financiamento de longo prazo;

iv) política de promoção comercial

v) promoção de gastos em pesquisa e desenvolvimento 
MORAIS, J.; AZEVEDO, J. Por uma abordagem institucionalista-evolucionária....

vi) educação e qualificação da mão-de-obra;

vii) regulação das concessões de serviço público;

biagi, 2002: 4)

viii) investimentos seletivos em infra-estrutura. (Além, Barros, Giam-

Por sua vez, as políticas de promoção a setores específicos, são direcionadas a indústrias particulares para atingir os resultados que são percebidos pelo Estado como sendo eficientes para a economia como um todo. Ressalta-se que apesar de ser direcionada a indústrias específicas, a política industrial em última instância tem como objetivo aumentar a eficiência da economia como um todo e não apenas a das indústrias selecionadas. São políticas estratégicas à medida que contribuem para o desenvolvimento de setores importantes para o sistema econômico como um todo, o que poderia não ocorrer caso as decisões estivessem à mercê apenas da racionalidade do mercado. Além, Barros e Giambiagi (2002), observaram que o "segredo" do sucesso das políticas setoriais de diferentes experiências nacionais esteve associado a uma seletividade eficiente e à cobrança de desempenho.

A importância conferida a cada uma dessas políticas depende também do referencial teórico do pesquisador e das variáveis selecionadas. Por exemplo, Além, Barros e Giambiagi (2002: 2), possuem uma visão mais ampla que incorpora as duas formas de política:

i) promoção de competitividade sistêmica; e ii) promoção de setores específicos. Esta divisão visa ressaltar o forte envolvimento das políticas macroeconômicas com as políticas industriais específicas, ou setoriais. Por um lado, um ambiente macroeconômico favorável é um pré-requisito para a promoção de novos investimentos na economia. Por exemplo, fica difícil de pensar em empresários entusiasmados em aumentar os seus gastos, tendo como pano de fundo uma economia marcada por forte incerteza quanto à evolução futura dos preços e da demanda. Por outro, as políticas industriais setoriais devem ser vistas como um instrumento que gera benefícios macroeconômicos e não como uma forma de beneficiar setores e/ou indústrias específicas.

Kupfer (2003), também enfatiza que é falsa a dicotomia entre política industrial horizontal e vertical. Na verdade, as políticas industriais bem sucedidas não se opõem ao mercado, mas tampouco se limitam a complementá-lo. Mas, chama a atenção para o fato de que as políticas de corte horizontal, ou seja, relacionadas a gestão macroeconômica podem ser necessárias mas não suficientes para promoverem o desenvolvimento econômico e social. Para este autor:

configurações industriais, estágios de desenvolvimento, desafios competitivos e capacidades de resposta são, em geral, setor-específicos. Dessa forma, políticas horizontais, ao contrário de neutras, repercutem de forma diferenciada entre os 
MORAIS, J.; AZEVEDO, J. Por uma abordagem institucionalista-evolucionária....

diversos setores industriais. Simetricamente, setores diferenciados podem apresentar necessidades similares, de sorte que as políticas verticais podem significar redundâncias, conflitos e má alocação de recursos. Calibrar com inteligência ambas as práticas de política industrial é, pragmaticamente, o objetivo a ser perseguido (Kupfer 2003: 294).

Como percebido, a política industrial tem a abrangência de um país, um sistema produtivo nacional. Mas, a relativa redução da sua capacidade de regulação do Estado, aliada ao ressurgimento de formas de organização econômica e política no nível subnacional (local/regional), induziram a uma re-territorialização do desenvolvimento econômico no contexto de uma nova economia internacional globalizada. Para Klink (2001), esta re-territorialização é entendida como um processo que busca garantir certas condições econômicas, políticas, sociais e culturais concentradas espacialmente num determinado local para uma inserção bem sucedida na economia global. Tem por base um conjunto de fatores relacionados à questão da proximidade espacial, a relação causal e circular entre crescimento econômico e localização de novas empresas, o papel crítico das estruturas sociais das regiões, os arranjos institucionais, os mecanismos de ampliação e difusão de conhecimento e, também, fatores culturais.

\section{Considerações finais}

Para Chang e Evans (2000), a mudança institucional depende da combinação de interesses e projetos ideológicos/culturais de difícil teorização. Portanto, alterar instituições requer mudanças de visões de mundo que são subjacentes às estruturas institucionais. Essa difícil teorização pode ser organizada de uma forma um pouco menos imprecisa, segundo Burlamaqui e Fagundes (1996), se nela forem introduzidos os conceitos de "isomorfismo" e "congruência". De forma prática, as possibilidades de política econômica são fortemente condicionadas pela estrutura institucional: grau de isomorfismo e; canais de comunicação existentes intra-setor privado e entre este e o setor público. Evans (2004), utilizando uma abordagem institucional comparativa, aproximase da visão de Burlamaqui e Fagundes. Segundo Evans, qualquer política econômica institucional comparativa do Estado deve oferecer uma visão clara, tanto da estrutura interna do Estado quanto do caráter das relações Estadosociedade. Na perspectiva neo-schupeteriana a questão do desenvolvimento enfatiza as mudanças qualitativas em termos tecnológicos, organizacionais e institucionais. Na articulação dos aspectos institucionais com a estrutura produtiva, mediadas sob a influência do binômio concorrência/progresso técnico, está a fonte das transformações econômicas que podem ser observadas a partir das distintas trajetórias tecnológicas possíveis dada esta articulação.

Posto isto, o desenvolvimento e o impacto da política industrial dependem de um conjunto complexo de interdependências sócio-institucionais 
que condicionam as trajetórias nacionais. Mas, as variações nas relações Estado-sociedade e na organização interna do Estado criam diferentes graus de capacidade para promover o desenvolvimento e as conseqüências da intervenção do Estado dependem de que tipo de intervenção é tentada, o tipo de Estado e o seu contexto. E este contexto, refere-se a um novo padrão de acumulação de capital com dominância financeira que vem desafiando a implementação de políticas de desenvolvimento industrial e tecnológico. Dentro do referencial aqui enfocado essas políticas devem considerar as inovações tecnológicas e a difusão territorial dessas inovações, a responsabilidade dos governos regionais e locais sobre os problemas territoriais, e a adoção de medidas para o desenvolvimento dos serviços de apoio à produção.

\section{Referências bibliográficas}

ALÉM, A. C.; BARROS, J. M.; GIAMBIAGI, F. (2002). "Bases para uma política industrial moderna”. In XIV Fórum Nacional. Estudos e Pesquisa n. 22. Rio de Janeiro: INAE.

BAPTISTA, M. A. C. (2000). Política industrial: uma interpretação heterodoxa. Campinas: Unicamp.IE (Coleção Teses).

BELL, J. F. (1961). História do pensamento econômico. Rio de Janeiro: Zahar Editores.

BLAUG, M. (1993). A metodologia da economia, ou como os economistas explicam. São Paulo: EDUSP.

BURLAMAQUI, L. e FAGUNDES, J. (1996). "Notas sobre a diversidade e regularidade no comportamento dos agentes econômicos: uma perspectiva neo-schumpeteriana”. In BARROS DE CASTRO, Antonio; POSSAS, Mário L.; PROENÇA, Adriano (Orgs). Estratégias empresariais na indústria brasileira: discutindo mudanças. Rio de Janeiro: Forense Universitária.

CAMPANÁRIO, M. S.; Marcello, M. (2004). "Fundamentos de uma nova política industrial”. In FLEURY, Tereza Leme; FLEURY, Afonso. Política industrial 1. Coleção biblioteca valor. São Paulo: Publifolha.

CONCEIÇÃO, O.A.C. (2001). Instituições, crescimento e mudança na ótica institucionalista. Teses FEE ; n. 1. Porto Alegre: Fundação de Economia e Estatística Siegfried Emanuel Heuser.

EVANS, P. B. (2004). Autonomia e parceria: Estados e transformação industrial. Rio de Janeiro: Editora UFRJ. 
MORAIS, J.; AZEVEDO, J. Por uma abordagem institucionalista-evolucionária....

EVANS, P. B.; CHANG, H-J. (2000). The Role of Institutions in Economic Change. URL [on-line]: <http://www.econ.cam.ac.uk/faculty/chang/c\&e-pdf.pdf>.

FIANI, R. (2003). Uma avaliação crítica da teoria do rent seeking. Seminário de Pesquisa IE/UFRJ, Rio de Janeiro.

GADELHA, C. A. G. (1999). Desenvolvimento e política industrial: uma perspectiva neo-schumpeteriana sistêmica e estrutural. Tese (Doutorado em Economia), Instituto de Economia, Universidade Federal do Rio de Janeiro - UFRJ.

GADELHA, C. A. G. (2002). Estado e inovação uma perspectiva evolucionista. Revista de Economia Contemporânea. Rio de Janeiro, vol 6, p. 85-117.

KLINK, J. J. (2001). A cidade-região: regionalismo e reestruturação no Grande ABC Paulista. Cocco Giuseppe (org.). Rio de Janeiro: DP\&A editora.

KUPFER, D. (2004). Tecnologia e emprego: são realmente antagônicos? In SICSÚ, J.; PAULA, L. F. e MICHEL, R. (Org). Desenvolvimentismo: um projeto nacional de crescimento com equidade social. São Paulo: Malone Barueri.

KUPFER, D. (2003). “Política industrial”. Econômica. Rio de Janeiro, vol. 5.

LAWSON, T. (2002). “Should Economics Be an Evolutionary Science? Veblen's Concern and Philosophical Legacy”. Journal of Economic Issues, vol. 36.

MONASTERIO, L. M. (1998). Guia para Veblen: um estudo acerca da economia evolucionária. Pelotas: EDUFPEL.

POSSAS, M. L. (1996). Competitividade: fatores sistêmicos e política industrial. In: BARROS DE CASTRO, Antonio; POSSAS, Mário L; PROENÇA, Adriano (Org.). Estratégias empresariais na indústria brasileira: discutindo mudanças. Rio de Janeiro: Forense Universitária.

RUTHERFORD, M. (2005). Wisconsin Institutionalism: John R. Commons and his students. Disponível em http://web.uvic.ca/ rutherfo/CommonsandhisstudentsShort.pdf.

THÉRET, B. (2003). “As instituições entre as estruturas e as ações”. Revista Lua Nova, n. 58.

VEBLEN, T. (1898). "Why is economics not an evolutionary science?" Cambridge Journal of Economics. vol. 22.

VILLEVAL, M-C. (1995). “Une théorie économique des institutions?”. In: BOYER, Robert; SAILLARD, Yves. Théorie de la régulation: l'état des savoirs. Paris: Éditions la découverte.

Recebido em: 15 de agosto de 2012 Aceito em: 15 de maio de 2013 